Article

\title{
Low-RPM Torque Converter (LRTC)
}

\author{
Andrej Savin *, Dana Salar and Erik Hultman
}

Department of Electrical Engineering, Division of Electricity, Uppsala University, Box 534, 75121 Uppsala, Sweden; dana.salar@angstrom.uu.se (D.S.); erik.hultman@angstrom.uu.se (E.H.)

* Correspondence: andrej.savin@angstrom.uu.se

\begin{abstract}
The concept concerned in this paper is based on energy conversion of the ocean waves via rotational generators. The objective of this research is to develop a new type of slow-motion converter. The LRTC device consists of a drum that is connected via wire to a floating buoy. The drum is connected to rotary generators. The generators are heavily braked when the direction of movement changes (up/down); this is because the generators have been charged the maximum load in order to obtain maximum output power. For upcoming improvement, the generators should have some power storage as flywheel. In the future experiments, the torque converter can even be tuned to rotate in resonance with the incoming waves, strongly increasing power absorption. Constant force springs are applied for this purpose. The focus of this project is, therefore, a new generation of wave power device for utility-scale energy conversion offering a cost of energy that can compete with established energy resources.
\end{abstract}

Keywords: wave energy conversion; torque converter; resonance frequency

Citation: Savin, A.; Salar, D.; Hultman, E. Low-RPM Torque Converter (LRTC). Energies 2021, 14, 5071. https://doi.org/10.3390/ en14165071

Academic Editors: Mehdi Neshat and Soheil Esmaeilzadeh

Received: 23 July 2021

Accepted: 12 August 2021

Published: 18 August 2021

Publisher's Note: MDPI stays neutral with regard to jurisdictional claims in published maps and institutional affiliations.

Copyright: (C) 2021 by the authors. Licensee MDPI, Basel, Switzerland. This article is an open access article distributed under the terms and conditions of the Creative Commons Attribution (CC BY) license (https:// creativecommons.org/licenses/by/ $4.0 /)$.

\section{Introduction}

Nowadays, more than 83 percent of energy conversion in the world is based on fossil fuels combustion, while scientists worldwide are debating the problem of Peak Oil [1] as well as the impact of emissions from fossil fuels. Most people agree that humanity needs to change to more sustainable sources. Interest and demand for clean, cheap, renewable power conversion techniques have increased. The ocean contains an abundant amount of renewable energy in different forms, and ocean waves represent one of them. Ocean waves arisen due to wind can transfer their energy for long distances without significant losses of energy, and waves keep on rolling for a longer time period although the wind has stopped blowing. This results in lower medium-term variations of wave energy density and a higher utilization factor compared with wind or solar energy [2,3]. Energy generation from waves along ocean coasts in the world has great potential to contribute to our electricity production, as well as those in Swedish waters [4].

The European Ocean Energy Road Map 2010-2050, published by EU in May 2010 [5], predicts the generation of over 15 percent of the EU energy demand, the creation of 470,000 new jobs, and the avoidance of over $136 \mathrm{MT} / \mathrm{MWh}$ of $\mathrm{CO}_{2}$ through the use of European ocean energy resources with a total, projected, installed capacity of $188 \mathrm{GW}$ by 2050 . To understand wave power potential, one should perhaps start by considering ocean waves in the context of other renewable energy sources. Since energy is the power generation integrated over time, the degree of utilization of intermittent renewable energy sources becomes a very important aspect. A typical example is comparing wave power to solar and wind power. Solar power has a typical degree of utilization of approximately 10-15 percent, wind power has about 25-30 percent, while wave power has at least 35 percent utilization with the potential of reaching 70 percent depending on the chosen site. That is a very important factor with a large impact on the revenue and profitability of renewable energy technology. The project is relevant to the environmental goals of Sweden, namely, to decrease negative environmental impact due to greenhouse gases. 
There are a number of wave energy technologies around the world [6-8].

Different degrees of efficiency have been properly discussed and are related to the ratio of power absorbed by the wave energy converter (WEC) to the power available at the ocean wave front before being transmitted to the power take-off system [9].

Research on WECs has been going on for decades. A variety of proposals have been developed to transform the energy of ocean waves into electricity, and some pilot installations were built worldwide. A lot of converters are presented as large and expensive facilities, often located on the water surface with a lot of sophisticated, sensitive equipment. Due to their size and complex system, they can encounter problems with handling the harsh wave climate.

A full-scale linear generator, see Figure 1a, has been developed at the Swedish Center for Renewable Electric Energy Conversion, Uppsala University. The first prototype was installed offshore at the Lysekil wave energy research site on the Swedish west coast in March 2006 [10-12]. Twelve full-scale WECs have been developed since.

Due to the huge energy stored in big waves, the floating structure can transfer critical force to the guiding system, see Figure $1 b$; as a result, the capsule experiences a bending moment.

A method for measurement and evaluation of the normal force acting on the guiding system was developed, which is the basis for the LRTC concept [13]. The azimuth and elevation angles between the WEC and the floating buoy were calculated. This makes it possible to estimate the magnitude of the load and direction of waves propagation on the guiding system from the ocean waves that is one of the key parameters for the design and construction of a low-RPM torque converter placed on the sea floor.

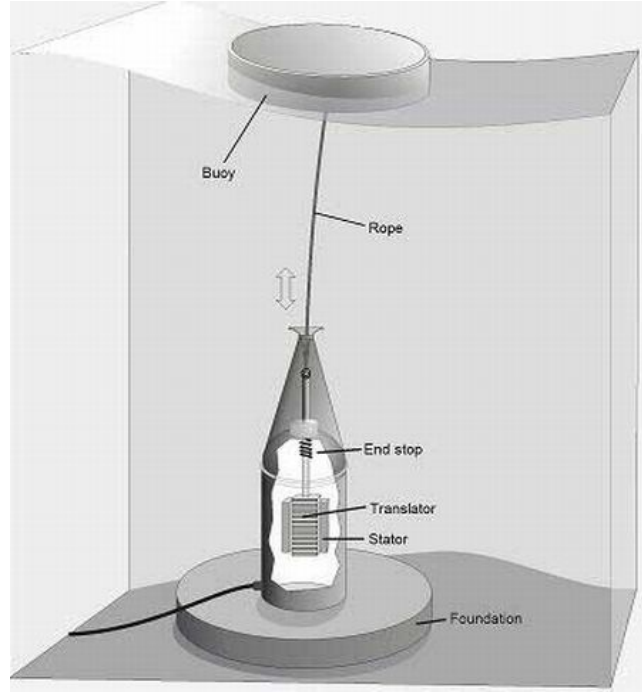

(a)

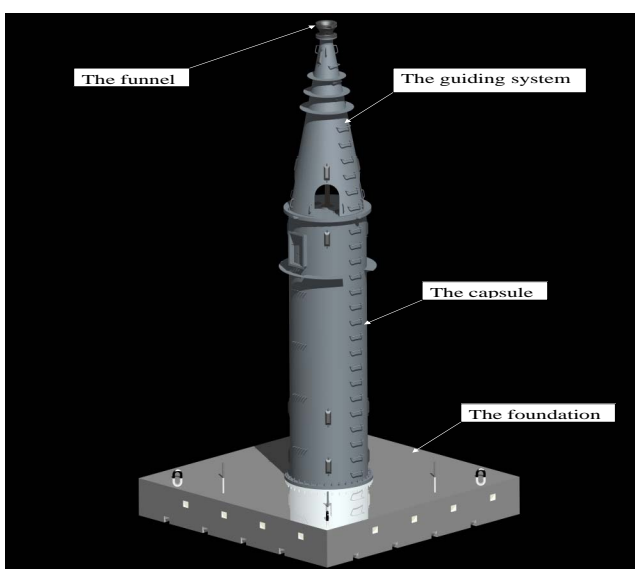

(b)

Figure 1. Linear Generator System.

The advantage of the LRTC concept over other concepts is that the device captures wave energy from both vertical and horizontal force components of ocean waves.

\section{The Proposed LRTC Concept}

The LRTC consists of two generators with one-way clutches for one-way rotation and a drum that is connected via wire to a buoy, see Figure $2 a, b$. 


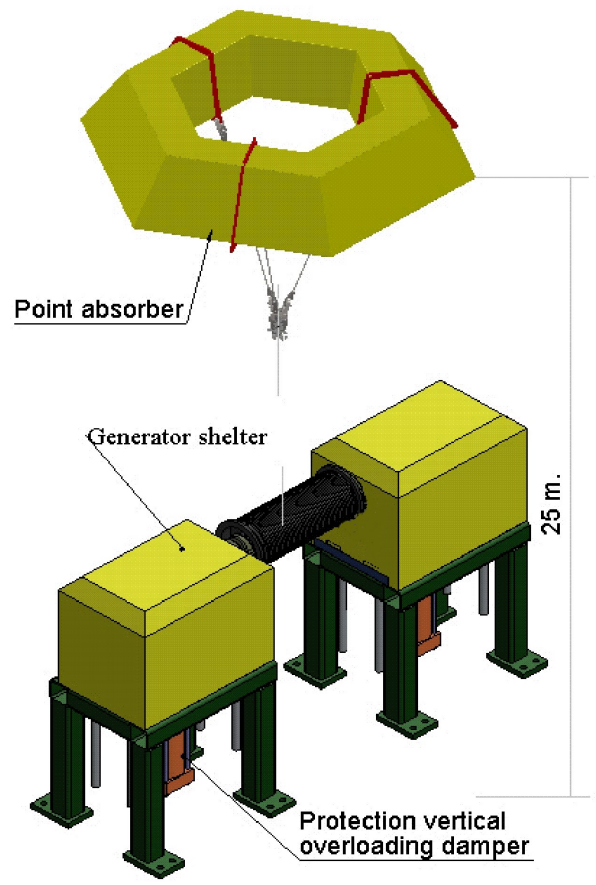

(a)

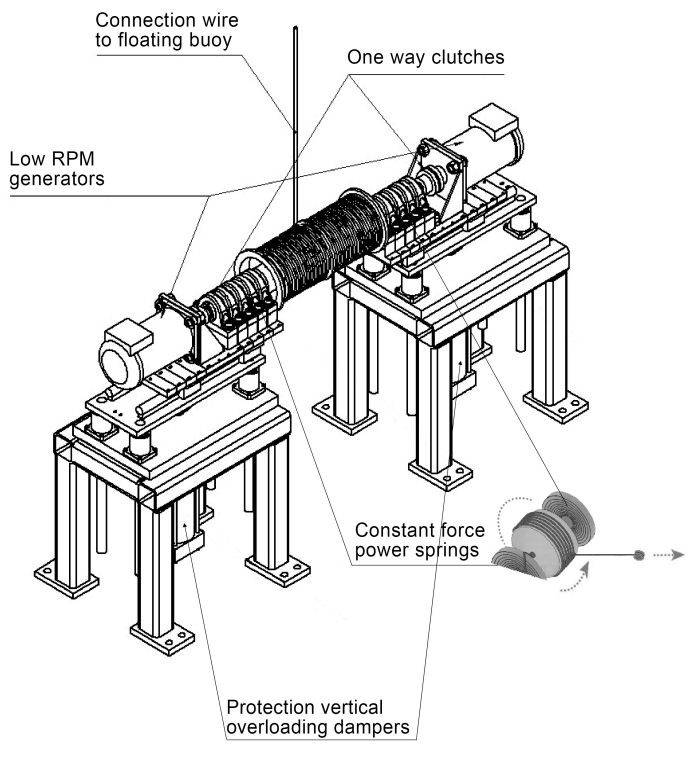

(b)

Figure 2. Low-RPM Torque Converter (LRTC) Concept.

When the wave goes up, only one generator is rotated. On the way down, the second generator is rotated while the first generator can still rotate.

Such a system allows minimizing power delay, which is unavoidable if only one generator is connected to the system. A series of high torque, long life, constant force power springs mounted on the drum's axis will draw back the drum on the wave trough. Generators will be mounted on a platform that can move vertically to some extent in the case of overloading from the waves or snatch loads in the rope. For this purpose, the platform will be equipped with protective vertical overloading dampers. The first big advantage with such a system is that almost all components required to construct the device already exist on the market. The next big advantage is that the device catches the wave's energy both from vertical and horizontal components of force.

The motions of the point absorber are more pronounced with maximum power absorption when the wave frequencies correspond to the natural frequency of the device [14].

In future experiments, the LRTC can even be tuned to rotate in resonance with the incoming waves, strongly increasing power absorption.

\section{Theory}

3.1. Second-Order Mechanical Systems

Second-order systems are defined by the following differential equation:

$$
\ddot{y}(t)+2 \xi \omega_{n} \dot{y}(t)+\omega_{n}^{2} y(t)=\omega_{n}^{2} K f(t)
$$

where $\xi$ is damping ratio, $\omega_{n}$ is natural frequency, and $K$ is static sensitivity. The input (or forcing) is $f(t)$ and the output is $y(t)$ in Equation (1).

\subsection{Mathematical Model of the LRTC Mechanical System}

Mathematical model of the LRTC mechanical system shown in Figure 3. 


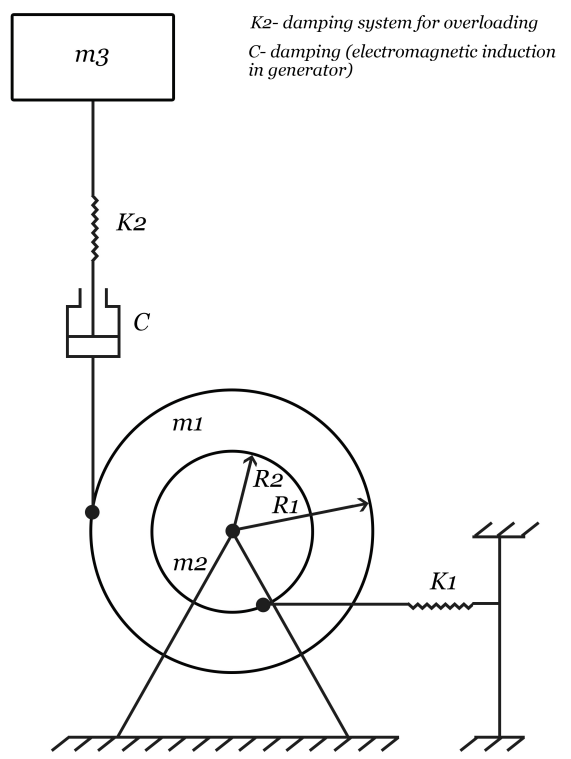

Figure 3. Mechanical system with drum pulley, translating body, linear-motion springs, and damper.

The model contains a rotary two-drum pulley; a vertically translating body (floating buoy); a horizontally translating spring; a damper (electromagnetic induction in generator); and one rigid, massless rod (the horizontal one has a spring connected to it). The pulley consists of two concentric drums that form a solid piece.

Figure 4 presents the free body diagrams of the rotary drum and translatory mass.
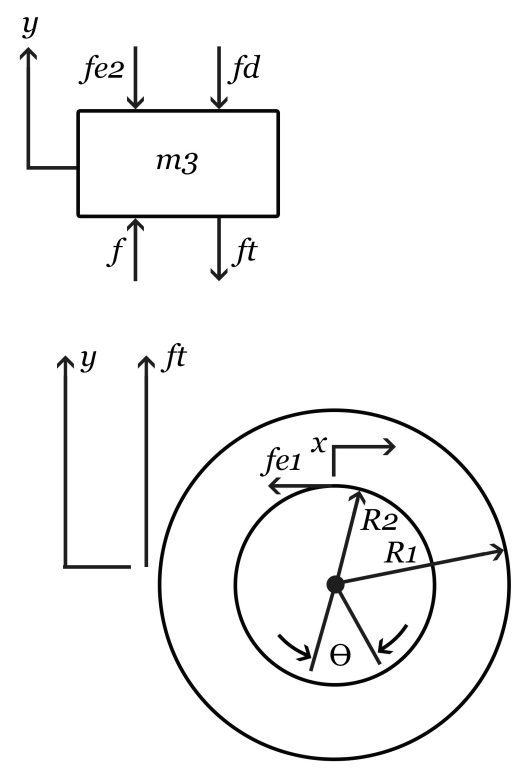

Figure 4. Free-body diagrams of the rotary drum and translatory body.

Newton's second law of motion is applied to the rotary drum and the translatory mass by taking into account the coordinates and forces shown in Figure 4, which results in

$$
\begin{array}{r}
I \ddot{\theta}=f_{t} R_{1}-f_{e 1} R_{2} \\
m_{3} \ddot{y}=f-f_{t}-f_{d}-f_{e 2}
\end{array}
$$


where $I$ is moment of inertia; $f_{t}$ is tension in the vertical direction; $f_{e 1}, f_{e 2}$ are spring elastic forces; and $f_{d}$ is damping force. The tangential displacements $x$ and $y$ can be approximated as

$$
x \approx R_{2} \theta ; y \approx R_{1} \theta
$$

By using these approximations, the elastic and damping forces of Equation (2) are formulated as

$$
\begin{array}{r}
f_{e 1}=k_{1} R_{2} \theta \\
f_{e 2}=k_{2} R_{1} \theta \\
f_{d}=c R_{1} \dot{\theta}
\end{array}
$$

The tension $f_{t}$ is substituted from the second part of Equation (2) into the first part of Equations (2) and (4) is also used, which yields the differential equation

$$
\begin{array}{r}
\left\{\frac{1}{2} m_{1} R_{1}^{2}+\frac{1}{2} m_{2} R_{2}^{2}\right\} \ddot{\theta}+c R_{1}^{2} \dot{\theta}+ \\
+\left(k_{1} R_{2}^{2}+k_{2} R_{1}^{2}\right) \theta=f R_{1}
\end{array}
$$

The natural frequency $\left(\omega_{n}\right)$, damping ratio $(\xi)$, and static sensitivity $(K)$ are obtained by comparing Equation (1) and Equation (5).

$$
\begin{gathered}
\omega_{n}=\sqrt{\frac{\left(k_{1} R_{2}^{2}+k_{2} R_{1}^{2}\right)}{\frac{1}{2} m_{1} R_{1}^{2}+\frac{1}{2} m_{2} R_{2}^{2}}} \\
\xi=\frac{c R_{1}^{2}}{2 \sqrt{\left(k_{1} R_{2}^{2}+k_{2} R_{1}^{2}\right)}\left\{\frac{1}{2} m_{1} R_{1}^{2}+\frac{1}{2} m_{2} R_{2}^{2}\right\}} \\
K=\frac{1}{\left(k_{1} R_{2}^{2}+k_{2} R_{1}^{2}\right)}
\end{gathered}
$$
ratio as

The resonance frequency $\left(\omega_{\text {res }}\right)$ can be obtained from natural frequency and damping

$$
\omega_{r e s}=\frac{\omega_{n}}{\sqrt{1-2 \xi^{2}}}
$$

This provides the opportunity for LRTC to be set to rotate in resonance with the incoming waves, strongly increasing power absorption.

\section{Experiment}

\subsection{Laboratory System for Reproducing Ocean Waves}

Water wave kinematics is a key research area in marine engineering.

According to [15], "the main difficulty encountered in trying to compare waves propagated numerically and experimentally was that the available numerical model required the wave height and velocity potential to be define in space at a particular time, whereas experimentally a driving time series is supplied to the wavemaker at a particular position".

The laboratory system for reproducing ocean waves reproduce the wave height, velocity, and frequency with the help of a 6-DOF articulated industrial robot of the Swedish brand ABB Robotics, see Figure 5.

Manipulator movement occurs between different positions, where information about the position, orientation, and joint configuration is defined for each mode. The operation as such can also be performed in different ways, where $\mathrm{CP}$ (continuous path) movement is the most precise principle. This principle is often used to create linear movement paths for the manipulator TCP (tool center point), which is the point that is positioned in space by 
the manipulator. In the laboratory system, the TCP is defined as the center of the end of the manipulator wrist (the connection point of the LRTC wire) and linear CP-motions are used.

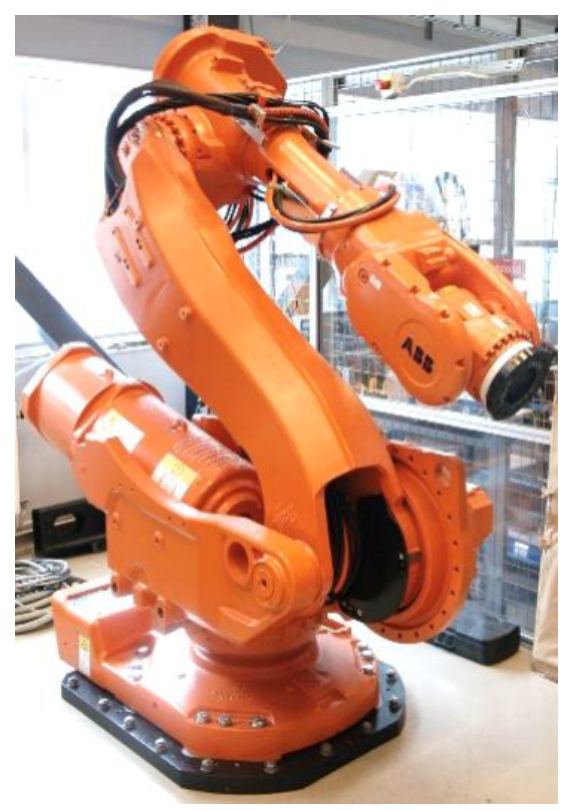

Figure 5. 6-DOF industrial robot manipulator used as wave-maker during the experiments.

This setup allows driving time series to be supplied to the wave-maker (articulated robot) at a particular position. Two different 1-DOF vertical sinusoidal movements were defined for the experiments: (i) amplitude $300 \mathrm{~mm}$ and period $4 \mathrm{~s}$, resulting in a maximum velocity of close to $500 \mathrm{~mm} / \mathrm{s}$; (ii) amplitude $300 \mathrm{~mm}$ and period $2 \mathrm{~s}$, resulting in a maximum velocity of close to $1000 \mathrm{~mm} / \mathrm{s}$. In the robot's programming, the motions were programmed as a large number of short linear movements with a sampling interval of $24 \mathrm{~ms}$ and tangential transitions. The movements both span 100 periods and were repeated several times to allow the system to warm up and to validate consistency of the results.

\subsection{Experimental Setup}

The experimental setup for a small-scale LRTC consists of two coreless permanent magnet generators (PMGs), see Table 1, and a drum that is connected via wire to a robot manipulator. Both PMGs are connected to the drum, see Figure 6a,b. The PMGs have advantages of low-speed direct driving, low starting torque, and no torque fluctuations.

Table 1. Characteristics of coreless PMG.

\begin{tabular}{ccc}
\hline Rated power & $K W$ & 0.05 \\
Rated speed & $R P M$ & 80 \\
Rated voltage & $V$ & 12 \\
Rated Line Current & $A$ & 2.41 \\
Start torque & $N / M$ & $<0.1$ \\
Efficiency & $\%$ & $>85$ \\
\hline
\end{tabular}

In this experiment, the 6-DOF industrial robot was used to simulate the buoy movement caused by sea waves.

The generator package set was mounted on a solid surface on the floor two meters from the robot's base point. 


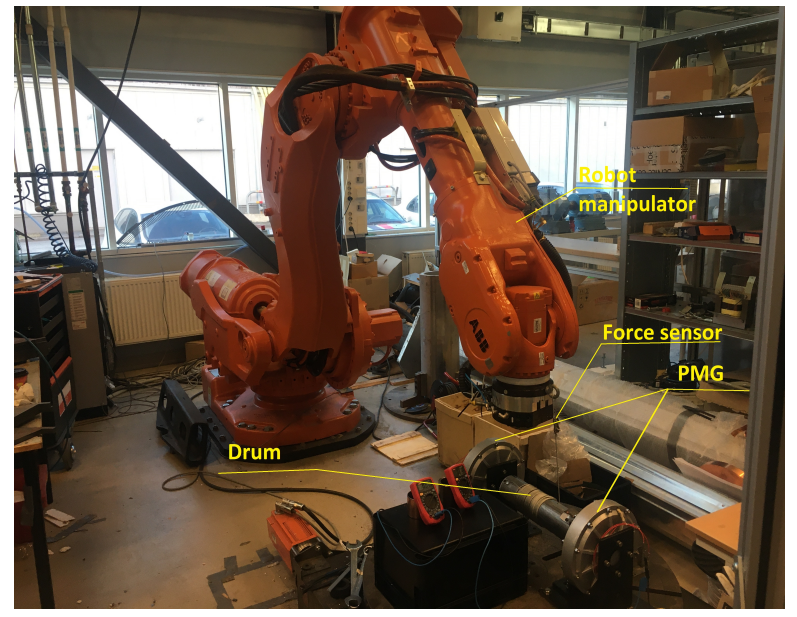

(a)

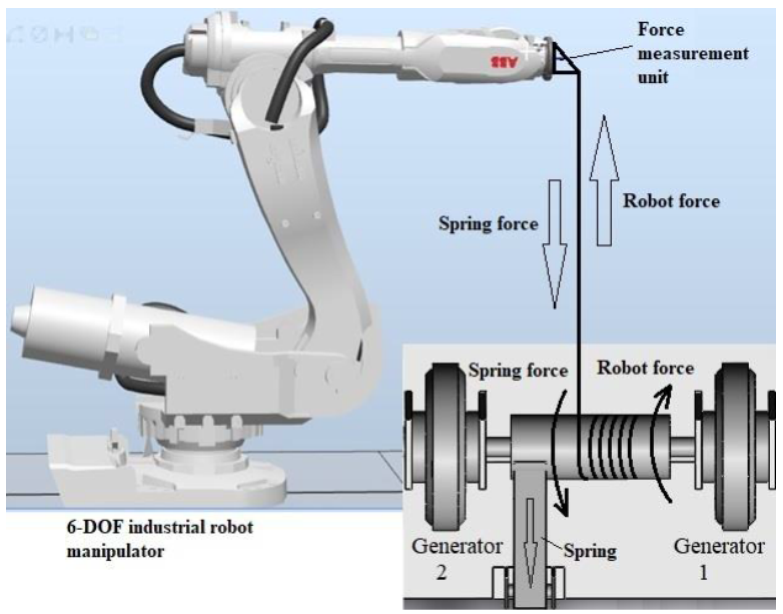

(b)

Figure 6. LRTC connected to articulated robot.

Force sensor was mounted between the 6-DOF industrial robot manipulator and a connection wire, where the force sensor measures the tensile force in the wire.

The robot pulls the line up; then, generator 1 spins clockwise and, when the robot moves in the opposite direction, the wire is pulled down with the spring force; then, generator 2 spins counter generator 1, see Figure $6 \mathrm{~b}$.

So, generator 1 rotates by the wire connected between the drum and the robot manipulator. Therefore, it only rotates from the robot force when the robot arm goes up. Generator 2 rotates by a constant force spring in opposite direction. For this, two one-way clutches are used, connected between the generator axis and the drum.

With repetitive movements, collaborations between the robot and the spring, the generators spin continuously in different directions.

The generators generate a three-phase alternating current (AC). The three-phase AC current passes through a rectifier bridge, where all three phases are rectified to a one-phase direct current (DC) and then loaded with a passive load (resistor load), see Figure 7.

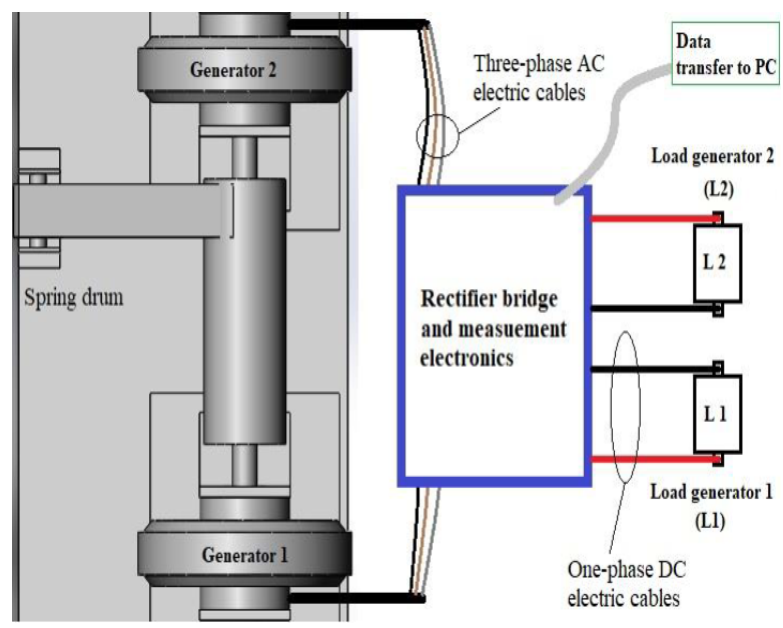

Figure 7. Generator's electronic and load setup.

The experimental system is monitored by various measurement and monitoring sensors that send the data via signal cables to a PC via a receiver unit connected to the PC. All data are processed with the National Instruments LabView software Company. In this experiment, the focus has been on the generator's properties and behaviors-i.e., the power from both generators verses traction force-from both the robot arms when pulling up the wire and the spring when pulling down the wire. In order to obtain a more 
accurate measurement of the utilization power from the generators, voltage and current were measured directly over loads L1 and L2, see Figure 7.

\section{Results}

The wave-energy device presented in this paper was developed following the observation of wave-amplification phenomena. A fully mathematical model has been developed.

An important building block in the construction of the model is utilization of the variational principle of the second-order mechanical system, from which the natural frequency $\left(\omega_{n}\right)$, damping ratio $(\xi)$, and static sensitivity $(K)$ are obtained.

The resonance frequency $\left(\omega_{\text {res }}\right)$ can be obtained from natural frequency and damping ratio. It gives the opportunity for LRTC to be set to rotate in resonance with the incoming waves, strongly increasing power absorption.

A laboratory proof-of-principle shows that the LRTC operates in a satisfactory manner.

The LRTC has been tested for two different velocities and time periods with the same amplitude equal to $300 \mathrm{~mm}$. Case (i): velocity $500 \mathrm{~mm} / \mathrm{s}$, amplitude $300 \mathrm{~mm}$, period $4 \mathrm{~s}$. Case (ii): velocity $1000 \mathrm{~mm} / \mathrm{s}$, amplitude $300 \mathrm{~mm}$, period $2 \mathrm{~s}$.

Figure 8 presents the LRTC lifting cycle series for case (i) in Figure 8a and case (ii) in Figure $8 \mathrm{~b}$ with synchronized force and power.

Figure 9 presents a detailed view of synchronized force and power for case (i) in Figure $9 \mathrm{a}, \mathrm{b}$ and case (ii) in Figure $9 \mathrm{c}, \mathrm{d}$.

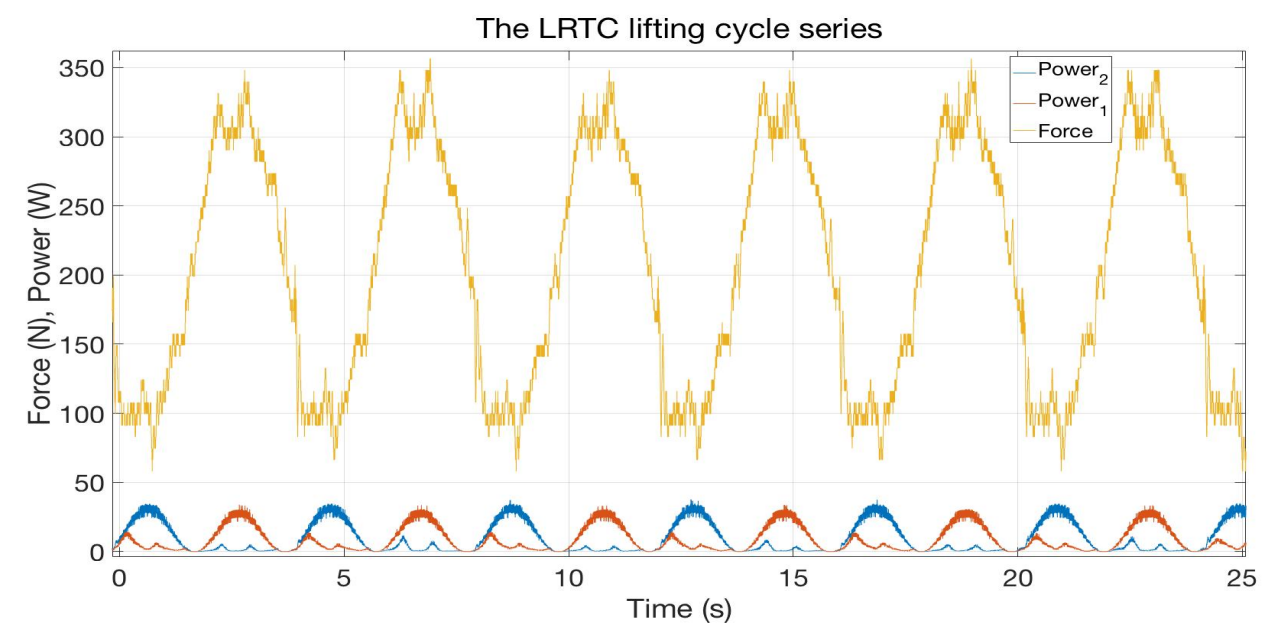

(a) Case (i): velocity $500 \mathrm{~mm} / \mathrm{s}$, amplitude $300 \mathrm{~mm}$, period $4 \mathrm{~s}$.

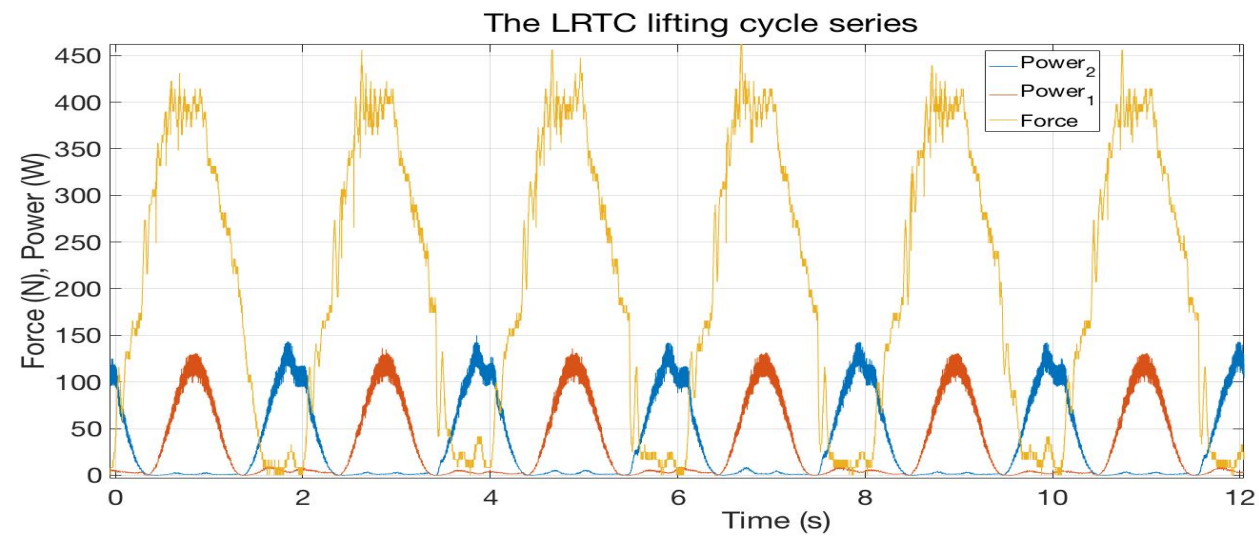

(b) Case (ii): velocity $1000 \mathrm{~mm} / \mathrm{s}$, amplitude $300 \mathrm{~mm}$, period $2 \mathrm{~s}$.

Figure 8. The LRTC lifting cycle series for case (i) and case (ii). 


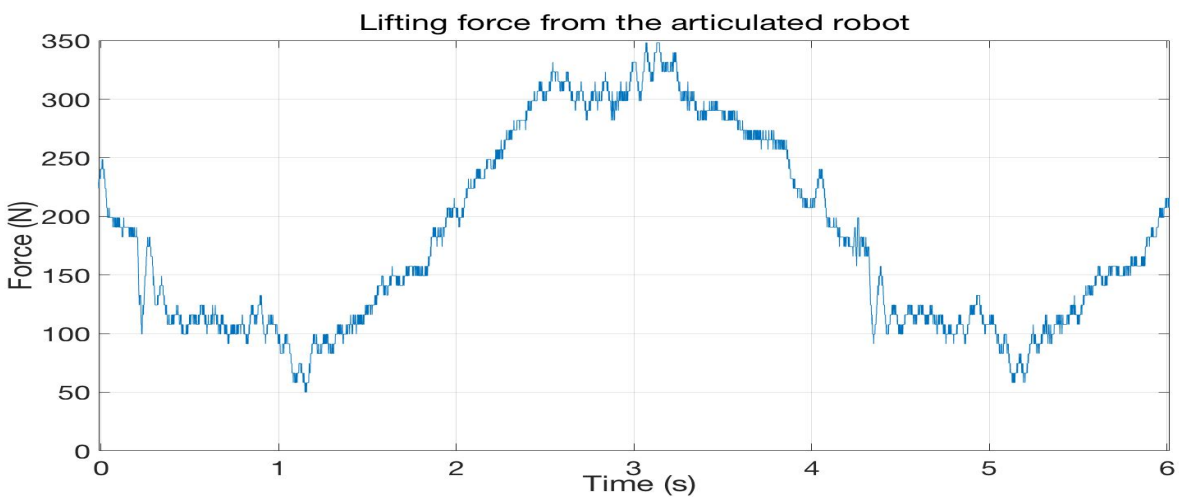

(a) Case (i): velocity $500 \mathrm{~mm} / \mathrm{s}$, amplitude $300 \mathrm{~mm}$, period $4 \mathrm{~s}$.

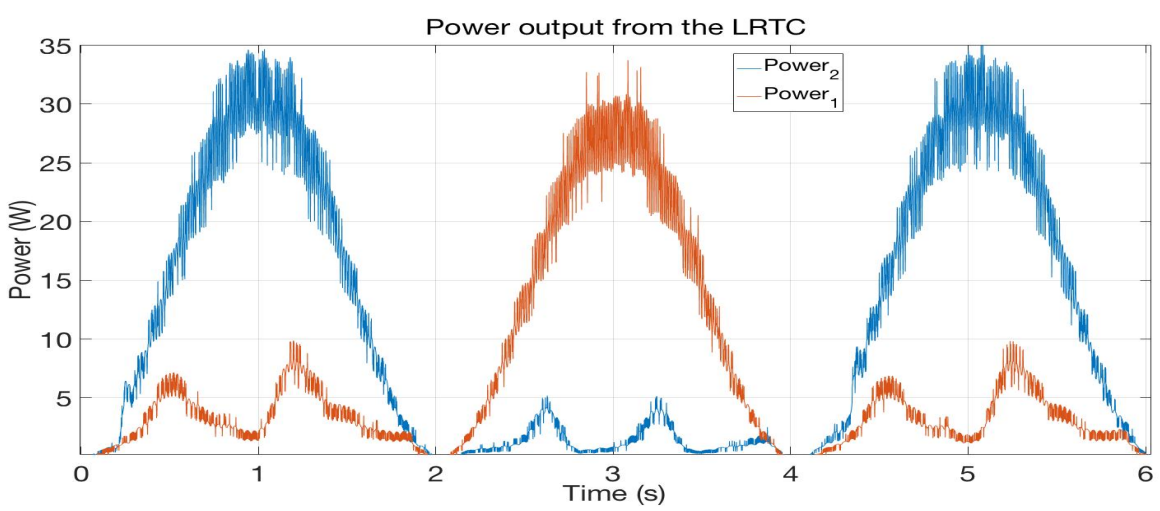

(b) Case (i): velocity $500 \mathrm{~mm} / \mathrm{s}$, amplitude $300 \mathrm{~mm}$, period $4 \mathrm{~s}$.

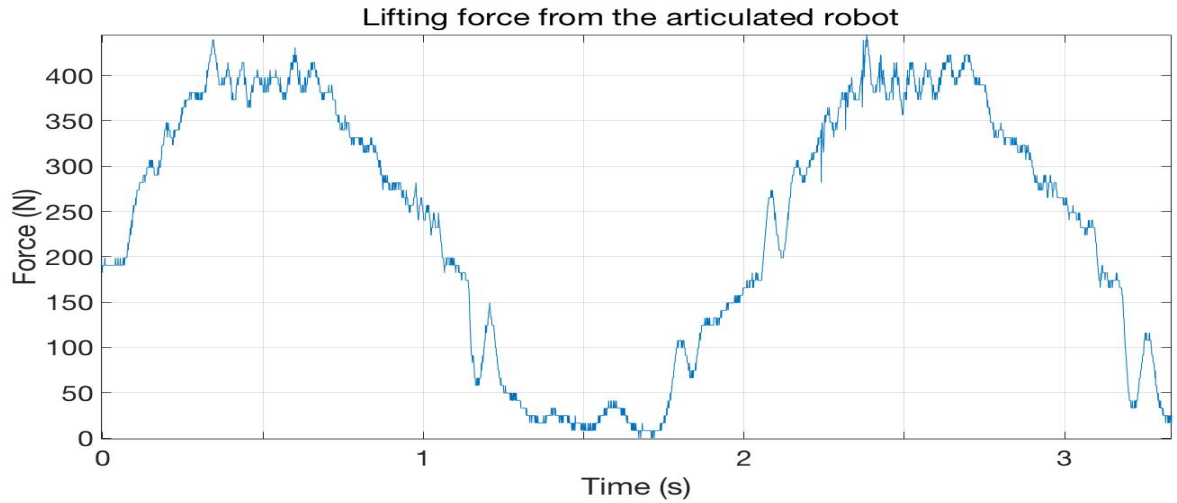

(c) Case (ii): velocity $1000 \mathrm{~mm} / \mathrm{s}$, amplitude $300 \mathrm{~mm}$, period $2 \mathrm{~s}$.

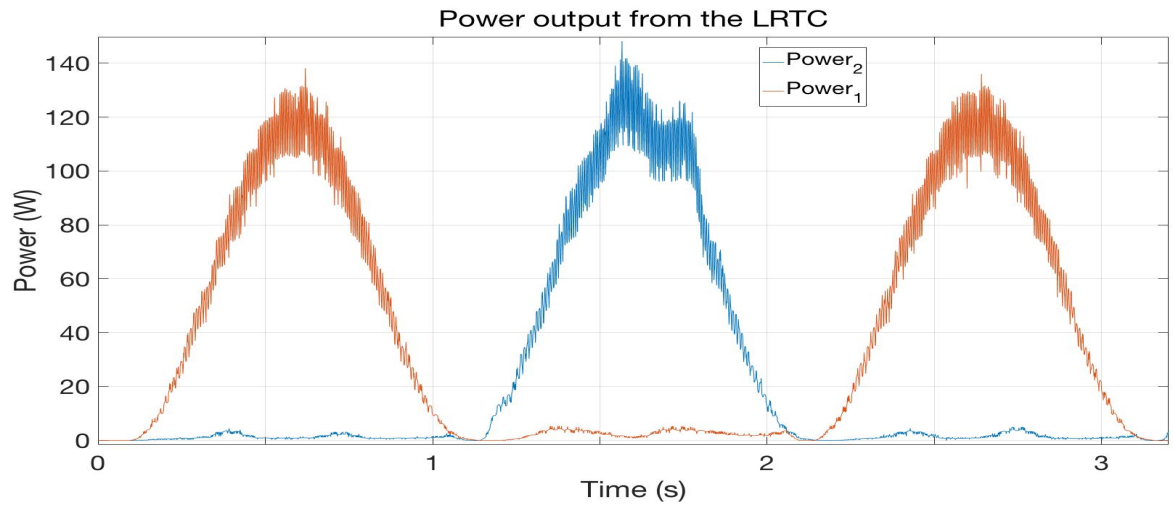

(d) Case (ii): velocity $1000 \mathrm{~mm} / \mathrm{s}$, amplitude $300 \mathrm{~mm}$, period $2 \mathrm{~s}$.

Figure 9. Detailed view of lifting cycles of the LRTC for case (i) and case (ii). 


\section{Conclusions}

Experimental results are in line with what is theoretically expected based on the presented data and the generator's specification.

The results of the experiment show the nature of the dependence on the robot's lifting force and frequency as well as the power from the LRTC. This corresponds to the principle in the concept itself and coincides with the parameters of the generator.

The force is nonzero when the period is $4 \mathrm{~s}$. In case (i), see Figures $8 \mathrm{a}$ and $9 \mathrm{a}$, because the system is pretensioned with a constant force spring in ready-for-experiment condition.

Force from the constant springs dropped to zero in case (ii), with a $2 \mathrm{~s}$ period, see Figures $8 \mathrm{~b}$ and $9 \mathrm{c}$. This means that the system experiences snatch load in the connection line between the LRTC and the articulated robot. The robot moves faster than the constant force spring. The system will be improved for the next experiment.

The generators were heavily braked when the direction of movement changed (up/ down); this is because the generators have been charged with maximum load in order to obtain maximum output power. For upcoming improvements, the generators should have some power storage as flywheel. The spring can also be replaced with a better system that does not vary the movement as it does now; this is clearly seen when the system is running and can be noticed in the output power curve, see Figure $9 \mathrm{~d}$ power $_{2}$, where generator two is running with the spring force.

\section{Future Work}

Future work plans include the development and performance of complementary laboratory experiments aiming comparison and further simulations for validation purposes.

Optimization studies are planned to improve device performance.

Research will focus upon the importance of the resource, which will be associated with the amplitude and frequency of robot manipulator to improve performance of the LRTC as well as experiments with flywheels connected to the axis of generators.

To achieve a more realistic laboratory system, actual wave climates could be programmed to the robot manipulator as well as movements in 3-6 DOF. A hydrodynamic model with force feedback could also be integrated to enable real-time compensation of buoy-water interaction.

In the next experiment, a flywheel will be mounted on each axis of rotation of the generator in order to smooth the power output.

In future work, the LRTC can even be tuned to rotate in resonance with the incoming waves, strongly increasing power absorption.

When these component optimizations are applied and understood, then an attempt to tackle the very difficult problem of complete device optimization will be considered.

Author Contributions: All the authors have made best efforts for LRTC project to ensure that the paper becomes qualified for publishing. Conceptualization, A.S.; Analysis, programming of 6-DOF industrial robot manipulator, E.H., D.S.; Data curation, experiment, D.S.; Funding acquisition, A.S.; Investigation, A.S., E.H. and D.S.; Methodology, A.S.; Project administration, A.S.; Validation, E.H. and D.S.; Visualization, D.S.; Writing — original draft, A.S.; Writing, review, editing, A.S., E.H. and D.S. All authors have read and agreed to the published version of the manuscript.

Funding: This research was funded by Carl Tryggers Stiftelse, Stockholm (Grant nr. CTS 16:404).

Acknowledgments: This work was financially supported by Carl Tryggers Stiftelse, Stockholm (Grant nr. CTS 16:404), StandUp for Energy and Uppsala University. The authors are grateful to ABB Corporate Research, for the donation of the robot used in the experiment.

Conflicts of Interest: The authors declare no conflicts of interest. 


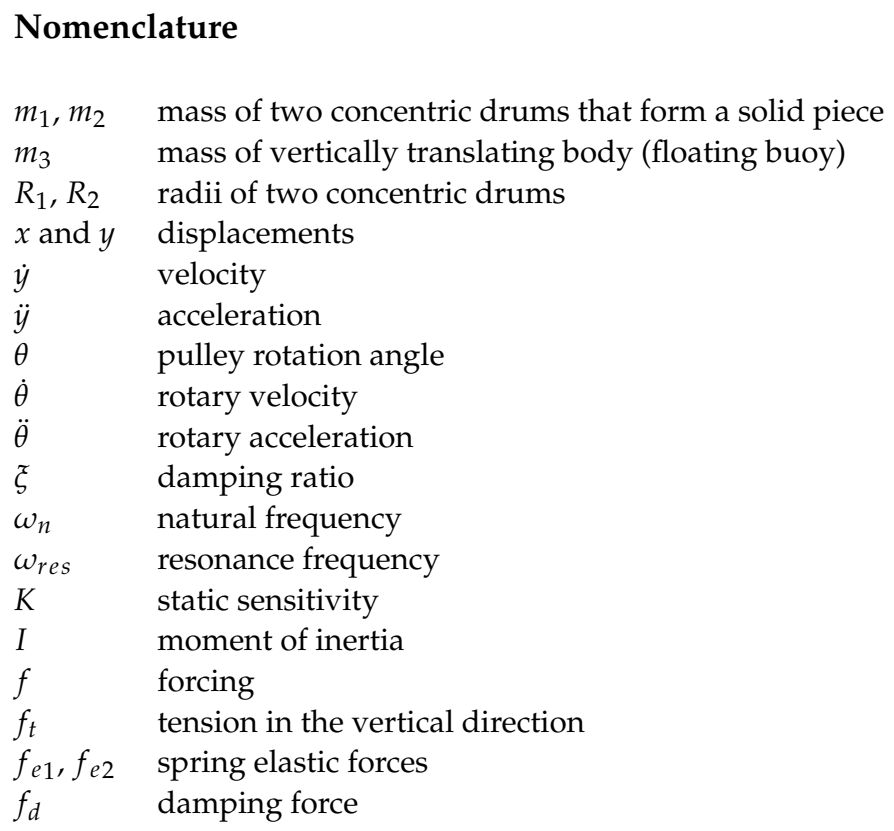

\section{References}

1. Bardi, U. Peak oil, 20 years later: Failed prediction or useful insight? Energy Res. Soc. Sci. 2019, 48, 257-261. [CrossRef]

2. Astariz, S.; Iglesias, G. Wave Energy vs. Other Energy Sources: A Reassessment of the Economics. Int. J. Green Energy 2016, 13, 747-755. [CrossRef]

3. Junejo, S.; Saeed, A.; Hameed, S. Energy Management in Ocean Energy Systems. Compr. Energy Syst. 2018, 5, 778-807.

4. Henfridsson, U.; Neimane, V.; Strand, K.; Kapper, R.; Bernhoff, H.; Danielsson, O.; Leijon, M.; Sundberg, J.; Thorburn, K.; Ericsson, E.; et al. Wave energy potential in the Baltic Sea and the Danish part of the North Sea, with reflections on the Skagerrak. Renew. Energy 2007, 32, 2069-2084. [CrossRef]

5. Nathalie Rousseau. Oceans of Energy_European Ocean Energy Roadmap 2010-2050. In OES-IA, OES, Ocean Energy, Implementing Agreement, IEA; ICOE. 2010. Available online: https:/ / www.icoe-conference.com/publication/oceans_of_energy_european_ ocean_energy_roadmap_2010_2050/(accessed on 11 August 2021).

6. Muraia, M.; Li, Q.; Funada, J. Study on power generation of single Point Absorber Wave Energy Converters (PA-WECs) and arrays of PA-WECs. Renew. Energy 2021, 164, 1121-1132. [CrossRef]

7. Azza, A.; Faiad, I. Gowaid linear generator technologies for wave energy conversion applications: A review. In Proceedings of the 2018 53rd International Universities Power Engineering Conference (UPEC), Glasgow, UK, 4-7 September 2018.

8. Elwood, D.; Yim, S.C.; Prudell, J.; Stillinger, C.; von Jouanne, A.; Brekken, T.; Brown, A.; Paaschs, R. Design, construction, and ocean testing of a taut-moored dual-body wave energy converter with a linear generator power take-off. Renew. Energy 2010, 35, 348-354. [CrossRef]

9. Aderinto, T.; Li, H. Review on Power Performance and Efficiency of Wave Energy Converters. Energies 2019, 12, 4329. [CrossRef]

10. Leijon, M.; Boström, C.; Danielsson, O.; Gustafsson, S.; Haikonen, K.; Langhamer, O.; Strömstedt, E.; Stålberg, M.; Sundberg, J.; Svensson, O.; et al. Wave Energy from the North Sea: Experiences from the Lysekil Research Site. Surv. Geophys. 2008, 29, 221-240. [CrossRef]

11. Leijon, M.; Waters, R.; Rahm, M.; Svensson, O.; Boström, C.; Strömstedt, E.; Engström, J.; Tyrberg, S.; Savin, A.; Gravråkmo, H.; et al. Catch the wave to electricity. IEEE Power Energy Mag. 2009, 7, 50-54. [CrossRef]

12. Hong, Y.; Eriksson, M.; Boström, C.; Pan, J.; Liu, Y.; Waters, R. Damping Effect Coupled with the Internal Translator Mass of Linear Generator-Based Wave Energy Converters. Energies 2020, 13, 4424. [CrossRef]

13. Savin, A.; Svensson, O.; Leijon, M. Azimuth-inclination angles and snatch load on a tight mooring system. Ocean Eng. 2012, 40, 40-49. [CrossRef]

14. Payne, G.S.; Taylor, J.R.M.; Bruce, T.; Parkin, P. Assessment of boundary-element method for modelling a free-floating sloped wave energy device. Part 1: Numerical modelling. Ocean. Eng. 2008, 35, 333-341. [CrossRef]

15. Tørum, A.; Gudmestad, O. Water Wave Kinematics; Series E; Applied Sciences; 1989; Volume 178. Available online: https: / / www.springer.com/gp/book/9789401067256 (accessed on 11 August 2021). 